\title{
All-fibre dual-wavelength thulium-doped fibre laser based on spatial filtering effect
}

\author{
${ }^{1,2}$ Azooz S. M., ${ }^{3}$ Hamida B. A., ${ }^{3}$ Khan S., ${ }^{4}$ Eltaif T., ${ }^{1}$ Jasim A. A., \\ ${ }^{2}$ Ahmad H. and ${ }^{2}$ Harun S. W. \\ ${ }^{1}$ Department of Electrical Engineering, Faculty of Engineering, University of \\ Malaya, 50603 Kuala Lumpur, Malaysia \\ ${ }^{2}$ Photonics Research Centre, University of Malaya, 50603 Kuala Lumpur, Malaysia \\ ${ }^{3}$ Department of Electrical and Computer Engineering, International Islamic \\ University Malaysia, Jalan Gombak, 53100 Kuala Lumpur, Malaysia \\ ${ }^{4}$ Faculty of Engineering \& Technology, Multimedia University, Jalan Ayer Keroh \\ Lama, 75450 Melaka, Malaysia, \\ e-mail:swharun@um.edu.my, azoozsalam@yahoo.com
}

Received: 14.01 .2014

\begin{abstract}
We report a room-temperature all-fibre dual-wavelength thulium-doped fibre laser that operates around $1900 \mathrm{~nm}$ and uses a spatial mode-beating filter in a ring configuration. By pumping the gain medium with an $800 \mathrm{~nm}$ laser and controlling the phase mismatch at the splicing points of a thulium-doped fibre, the two output lines are obtained at 1844.8 and $1852.0 \mathrm{~nm}$, with the corresponding signal-to-noise ratios of 30 and $21 \mathrm{~dB}$. The threshold pump power is $109.3 \mathrm{~mW}$. At the maximum pump power of $131.7 \mathrm{~mW}$, the output powers are 0.297 and $0.038 \mathrm{~mW}$ for the 1844.8 and $1852.0 \mathrm{~nm}$ laser lines, respectively.
\end{abstract}

Keyword: fibre lasers, dual-wavelength lasers, thulium-doped fibre lasers

PACS: $42.55 . \mathrm{Wd}, 42.60 . \mathrm{Da}$

UDC: $535.374+621.375 .826+681.7 .068$

\section{Introduction}

A thulium-doped fibre laser (TDFL) operating near $2 \mu \mathrm{m}$ has drawn a great interest in the recent years since it offers a possibility for combining high efficiency and high output power with eyesafe operation. In addition, it suggests a number of specific applications associated exclusively with its infrared wavelength, e.g. in the fields of remote sensing and biomedicine [1-4]. As a result of a so-called cross-relaxation process, the efficient laser operation at $2 \mu \mathrm{m}$ can be achieved by using the ${ }^{3} \mathrm{~F}_{4} \rightarrow{ }^{3} \mathrm{H}_{6}$ pump transition of thulium ions in the vicinity of $800 \mathrm{~nm}$. In this process, two ground-level thulium ions can be excited to the upper lasing level of the ${ }^{3} \mathrm{~F}_{4} \rightarrow{ }^{3} \mathrm{H}_{6}$ transition by absorbing a single pumping photon with the energy corresponding to approximately $800 \mathrm{~nm}$. This suggests that every excited $\mathrm{Tm}^{3+}$ ion located at the ${ }^{3} \mathrm{H}_{4}$ level can produce two $\mathrm{Tm}^{3+}$ ions at the upper lasing level ${ }^{3} \mathrm{~F}_{4}$ [5]. Besides, inexpensive and stable low-power fibre lasers working in allfibre configuration in the wavelength region of 1800-2100 nm can have a tremendous potential for such applications as sensing of toxic gases, due to specific features of infrared absorption of those gases.

All-fibre dual-wavelength fibre lasers have also gained a great attention of researchers and technologists due to their potential applications in microwave photonics, fibre sensing systems, optical instrument testing, and optical signal processing [6-8]. Up to date, various methods have been suggested and demonstrated to achieve a dual-wavelength lasing. These are the techniques 
that involve a dual-cavity configuration or a twin-peak reflection grating. However, most of the lasers developed up to now operate in the region of 1.00-1.55 $\mu \mathrm{m}$. For the longer-wavelength region nearby $2 \mu \mathrm{m}$, the fibre components in need are not as readily available as those suitable for generation at $1.00 \mu \mathrm{m}$ or even $1.55 \mu \mathrm{m}$. Very recently a solid-state microchip laser on Tm, Ho: $\mathrm{YVO}_{4}$ has been built [9]. It simultaneously operates at 2041.3 and $2054.6 \mathrm{~nm}$ in the dualwavelength regime. Due to its compactness and robustness, an all-fibre laser able to generate in the $2 \mu \mathrm{m}$ band is still urgently expected to come in practice.

In an earlier work, Zhou et al. [10] have demonstrated a room-temperature all-fibre dualwavelength TDFL based on a cascaded fibre Bragg grating array. In this article, we develop a room-temperature all-fibre dual-wavelength TDFL operating near $1900 \mathrm{~nm}$, which uses a simpler approach based on a spatial filter generated due to mismatch at the splicing points of a thuliumdoped fibre (TDF).

\section{Configuration}

A scheme of our dual-wavelength TDFL is shown in Fig. 1. The laser is constructed using a simple ring cavity, in which a $2 \mathrm{~m}$ long TDF is used as an active medium. The TDF used by us has the core and cladding diameters of $9 \mu \mathrm{m}$ and $125 \mu \mathrm{m}$ respectively, the cut-off wavelength of $1750 \mathrm{~nm}$, and the numerical aperture of 0.15 . The absorption of thulium ions in this fibre has a peak at $793 \mathrm{~nm}(27 \mathrm{~dB} / \mathrm{m})$. The TDF is pumped by an $800 \mathrm{~nm}$ laser diode via an $800 / 2000 \mathrm{~nm}$ wavelength division multiplexer. The operating wavelength of our TDFL is determined by a spatial filter, which is formed by controlling the phase mismatch at the splicing points of the TDF. The mismatch creates oscillations within the TDF. The output of the dual-wavelength laser is tapped from a $10 \mathrm{~dB}$ output coupler, allowing for 90 per cent of the light to remain in the cavity. The output spectrum and the power of the laser are measured with an optical spectrum analyser.

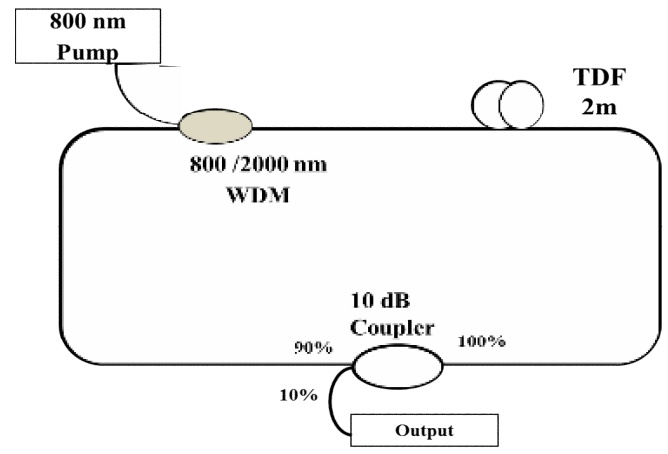

Fig. 1. Experimental setup of our dual-wavelength TDFL: crosses correspond to splicing points of the TDF (see the text).

Fig. 2 shows the transmission spectrum of the spatial filter. In our experiments, a broadband $1550 \mathrm{~nm}$ source of amplified spontaneous emission is launched into the setup from the input port of the wavelength division multiplexer coupler, and the output spectrum is measured after a $10 \mathrm{~dB}$ coupler, using an optical spectrum analyser. As we control precise details of the splicing between the single-mode fibre and the TDF, the power oscillations occur within the TDF, thus producing some wavelength-dependent losses. As a result of specific transmission function of the spatial mode-beating filter, the spectrum at the output signal has a comb-type structure shown in Fig. 2. As seen from Fig. 2, the spacing between the two neighbouring peaks is measured to be around $1.8 \mathrm{~nm}$. 


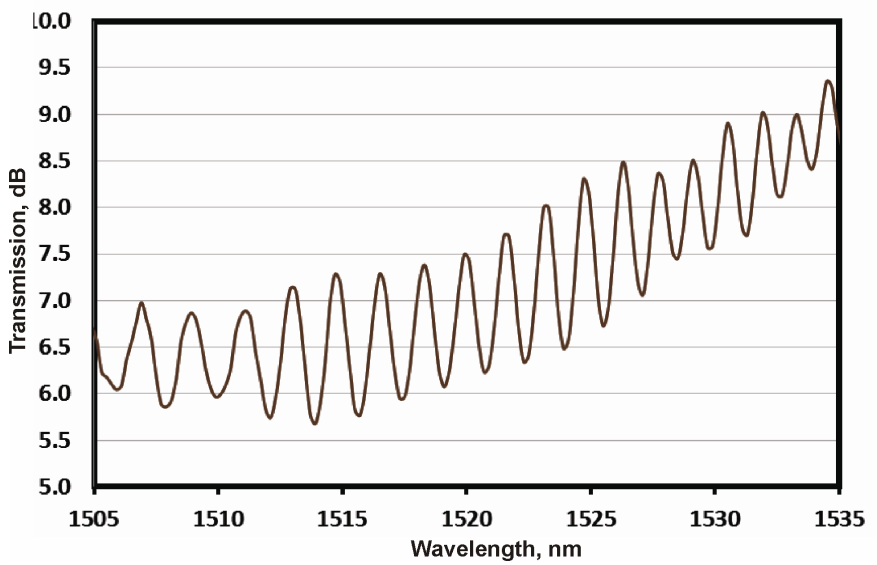

Fig. 2. Comb-type spectral structure of signal produced by our spatial modebeating filter.

\section{Results and discussion}

As the TBF is pumped, an amplified spontaneous emission is generated in the vicinity of $1900 \mathrm{~nm}$ via both spontaneous and stimulated emission processes. The thulium ions are excited to ${ }^{3} \mathrm{~F}_{4}$ level as they absorb the pumping photons to create the population inversion between the ${ }^{3} \mathrm{H}_{6}$ and ${ }^{3} \mathrm{~F}_{4}$ levels. Then they drop to the ground state $\left({ }^{3} \mathrm{H}_{6}\right)$ and emit light at $1.9 \mu \mathrm{m}$. The amplified spontaneous emission oscillates in the ring cavity, resulting in a laser that operates according to the transmission characteristic of the spatial mode-beating filter. Since the filter has a wide bandwidth, the regime of dual-wavelength laser output can easily be implemented. Due to the transmission characteristic of the filter, the signals at two different wavelengths can oscillate in the cavity whenever the difference of the cavity losses for them are somewhat reduced. By adjusting polarization state of the light propagating in the laser cavity, one can tune the cavity losses for these two wavelengths to seek dual-wavelength oscillations with the aid of the TDF, whose gain broadening behaves inhomogeneously. Fig. 3 shows the output spectrum of the TDFL recorded by the optical spectrum analyser at different pump powers. As seen from Fig. 3, the dual-wavelength output lines are obtained at 1844.8 and $1852.0 \mathrm{~nm}$, so that their spacing is equal to $7.2 \mathrm{~nm}$. This spacing is four times larger than that associated with the spatial filter at $1550 \mathrm{~nm}$. At the pump power as low as $124.5 \mathrm{~mW}$, the signal-to-noise ratios for the 1844.8 and $1852.0 \mathrm{~nm}$ lines are respectively equal to 30 and $21 \mathrm{~dB}$, with the $3 \mathrm{~dB}$ bandwidth being approximately equal to $2.0 \mathrm{~nm}$.

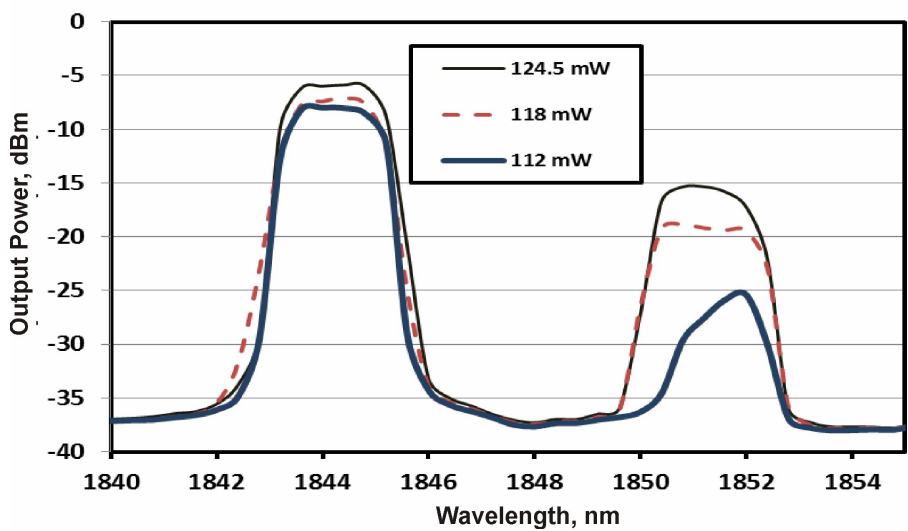

Fig. 3. Output spectra of our TBFL at three different pump powers indicated in the legend.

The relationships between the pump power and the peak powers of the dual-wavelength output lines located at $1844.8 \mathrm{~nm}$ and $1852.0 \mathrm{~nm}$ are shown in Fig. 4. The dual-wavelength laser starts to lase above the threshold pump power of $109.3 \mathrm{~mW}$. Then the both output-peak powers 
increase linearly with increasing pump power. At the maximum pump power of $131.7 \mathrm{~mW}$ dealt with in the present experiments, the 1844.8 and $1852.0 \mathrm{~nm}$ laser lines have the maximum output powers of 0.297 and $0.038 \mathrm{~mW}$, respectively. Fig. 5 shows the output optical spectrum of our dual-wavelength laser for the case when the scanning interval is $10 \mathrm{~min}$. In our experiments, the dual-wavelength operation can be stable for more than two hours if only the temperature variations and the mechanical vibrations are kept reasonably small, as with standard laboratory facilities. As seen from Fig. 4, the corresponding difference for each laser wavelength is less than $1 \mathrm{~dB}$, thus pointing to enough stability of the output. No other lasing modes have been observed inside the thulium gain band. Since the operating laser wavelengths are determined only by the spatial filter, they can be tuned by controlling the mismatch between the fibre associated with the wavelength division multiplexer and the TDF, or by using some other techniques.

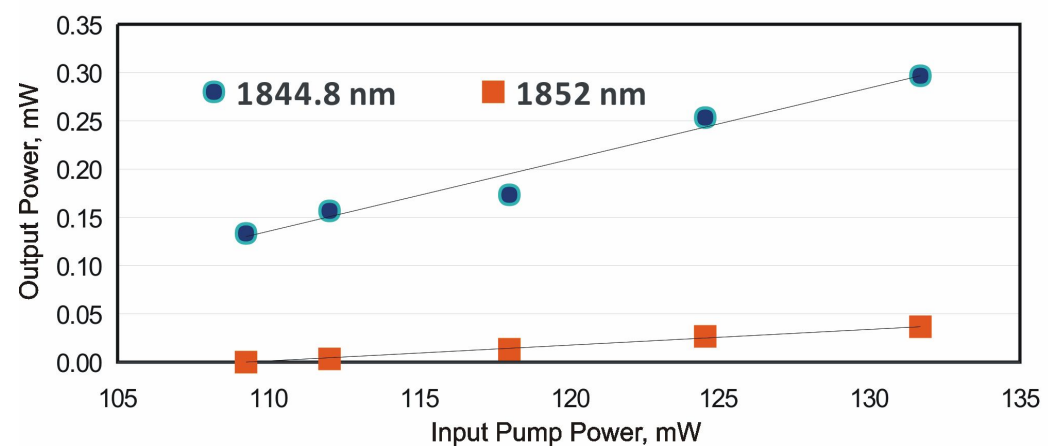

Fig. 4. Dependences of peak output powers of the two laser lines on the input pump power.

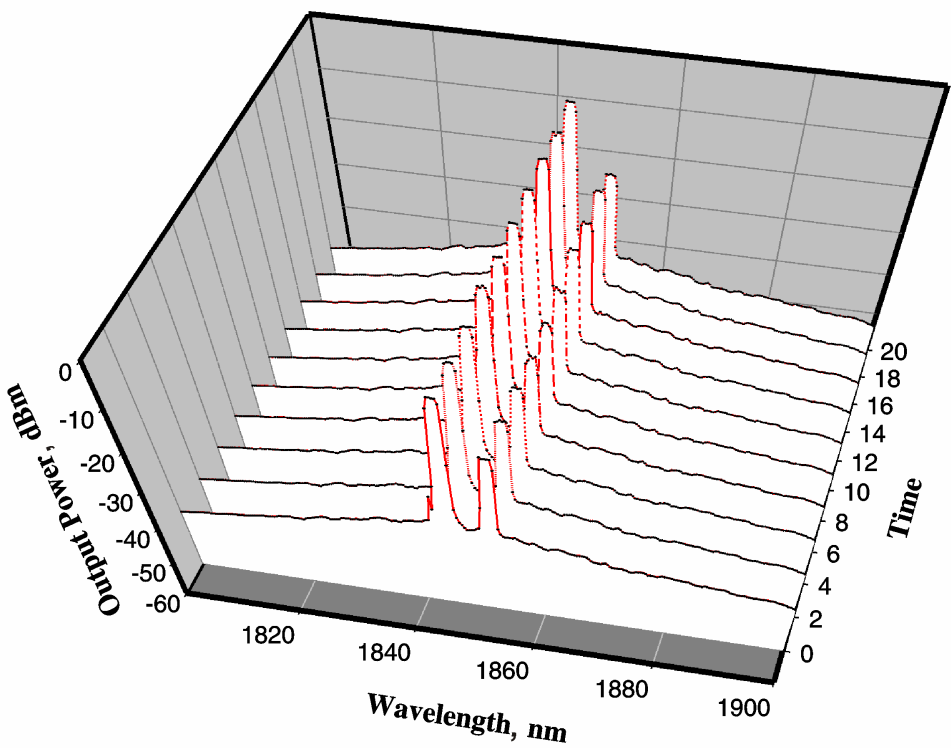

Fig. 5. Output power spectra of our TDFL taken with 10 min periods between frames to illustrate stability of the laser.

\section{Conclusion}

Let us summarize the main results of this report. An all-fibre dual-wavelength TDFL operating near $1900 \mathrm{~nm}$ is built. It functions at the room temperature and uses a spatial filter. The filter is designed for controlling the phase mismatch at the splicing points of the TDF. The laser developed by us generates the dual-wavelength output lines at 1844.8 and $1852.0 \mathrm{~nm}$, i.e. the wavelength spacing amounts to $7.2 \mathrm{~nm}$. The corresponding optical signal-to-noise ratios are 30 and $21 \mathrm{~dB}$, 
respectively. The device starts to lase at both of the lines above the threshold pump power of $109.3 \mathrm{~mW}$. When the pump power reaches the maximal value of $131.7 \mathrm{~mW}$ studied in our experiments, the output powers of the laser lines corresponding to 1844.8 and $1852.0 \mathrm{~nm}$ are equal to 0.297 and $0.038 \mathrm{~mW}$, respectively.

\section{Acknowledgments}

This work was supported by the MOHE under the ERGS grant scheme (Grant No: ER012-2012A). B A Hamida would like to thank the International Islamic University, Malaysia for his fellowship.

\section{References}

1. Jiang S, Recent progress on 2-micron fiber lasers. In: Proc. Optical Fiber Communication Conf., pp. 1-3 (2011).

2. Harun S W, Halder A, Paul M C, Ali S M M, Saidin N, Damanhuri S S A, Ahmad H, Das S, $\mathrm{Pal} \mathrm{M}$ and Bhadra S K, 2012. Ytterbium-sensitized thulium-doped fiber laser with a singlemode output operating at 1900-nm region. Chinese Opt. Lett. 10: 101401.

3. Zhang Z, Boyland A J, Sahu J K, Clarkson W A and Ibsen M, 2011. High-power singlefrequency thulium-doped fiber DBR laser at $1943 \mathrm{~nm}$. IEEE Photon. Technol. Lett. 23: 417419.

4. Harun S W, Saidin N, Damanhuri S S A, Ahmad H, Halder A, Paul M C, Das S, Pal M and Bhadra S K, 2012. Fiber laser at 2 micron region using double-clad thulium/ytterbium codoped yttria-alumino-silicate fiber. Laser Phys. Lett. 9: 50-53.

5. Fatehi H, Emami S D, Zarifi A, Zahedi F Z, Mirnia S E, Zarei A, Ahmad H and Harun S W, 2012. Analytical model for broadband thulium-bismuth-doped fiber amplifier. IEEE Quant. Electron. 48: 1052-1058.

6. Jeon M Y, Kim N, Shin J, Jeong J S, Han S, Lee C W, Leem Y A, Yee D, Chun H S and Park $\mathrm{K} \mathrm{H}, 2010$. Widely tunable dual-wavelength $\mathrm{Er}^{3+}$-doped fiber laser for tunable continuouswave terahertz radiation. Opt. Express. 18: 12291-12297.

7. Ahmad H, Zulkifli M Z, Latif A A and Harun S W, 2009. Tunable dual wavelength fiber laser incorporating AWG and optical channel selector by controlling the cavity loss. Opt. Commun. 282: 4771-4775.

8. Li H, Ding H and Chan K T, 1997. Erbium-doped fiber lasers for dual-wavelength operation. Electron. Lett. 33: 52-53.

9. Zhang C H, Yao B Q, Li G, Wang Q, Ju Y L, and Wang Y Z, 2010. $2041.3 \mathrm{~nm} / 2054.6 \mathrm{~nm}$ simultaneous dual-wavelength single-longitudinal-mode Tm, Ho: $\mathrm{YVO}_{4}$ microchip laser. Laser Phys. 20: $1564-1567$.

10. Zhou P, Wang X L, Ma Y X, Han K and Liu Z J, 2011. Stable all-fiber dual-wavelength thulium-doped fiber laser and its coherent beam combination. Laser Phys. 21: 184-187.

Azooz S.M., Hamida B.A., Khan S., Eltaif T., Jasim A.A., Ahmad H. and Harun S.W. 2014. Allfibre dual-wavelength thulium-doped fibre laser based on spatial filtering effect. Ukr.J.Phys.Opt. 15: 79-83.

Анотація. Описано двохвильовий волоконний лазер, який працює за кімнатної температури на легованому тулісм оптичному волокні та випромінює поблизу 1900 нм, використовуючи просторовий фільтр на битті мод у кільцевій конфігурачії. Шляхом нагнітання активного середовища за допомогою лазера з довжиною хвилі 800 нм $i$ керування фазовим неузгодженням на точках стиків волокна, легованого тулієм, одержано вихідні лінії випромінювання з довжинами хвиль 1844,8 і 1852,0 нм, а відповідні відношення сигнал/шум становили 30 і 21 дБ. Порогова потужність нагнітання складала 109,3 мВт. 3 а максимальної потужності нагнітання 131,7 мBт потужність на виході становила 0,297 $i$ 0,038 мВт відповідно для лазерних ліній 1844,8 і 1852,0 нм. 